\title{
SINTESIS SURFAKTAN ALKIL POLIGLIKOSIDA DARI GLUKOSA DAN DODEKANOL DENGAN KATALIS ASAM
}

\author{
Anastasia Wulan Pratidina Swasono, Putri Dei Elvarosa Sianturi, Zuhrina Masyithah \\ Departemen Teknik Kimia, Fakultas Teknik, Universitas Sumatera Utara, \\ Jl. Almamater, Kampus USU, Medan 20155, Indonesia \\ Email : wulanpsw@yahoo.com
}

\begin{abstract}
Abstrak
Alkil poliglikosida (APG) merupakan surfaktan nonionik ramah lingkungan dan mudah terurai yang dapat diperoleh dengan mereaksikan senyawa glukosa dan fatty alkohol. Tujuan penelitian ini adalah mengetahui pembuatan surfaktan alkil poliglikosida dari glukosa dan dodekanol dan mengetahui pengaruh konsentrasi katalis dan rasio molar substrat. Kondisi proses penelitian ini adalah rasio molar substrat glukosa dan dodekanol: 1:1; 1:2; 2:1 ( $\mathrm{mol} / \mathrm{mol})$, konsentrasi katalis asam klorida 0,3 M; 0,4 M; 0,5 M; 0,6 M pada temperatur $100{ }^{\circ} \mathrm{C}$. Analisa yang dilakukan dalam penelitian ini menggunakan spektroskopi FT-IR, analisa tegangan permukaan (Critical Micelle Concentration) dan nilai HLB (Hidrophylic-Lipophylic Balance). Pada sintesis alkil poliglikosida, konsentrasi katalis yang baik dalam mempercepat waktu reaksi adalah 0,6 M, tegangan permukaan (CMC) terbesar pada rasio glukosa dan dodekanol 2:1 sebesar 70,7945\% dan nilai HLB tertinggi sebesar 7,31 pada perbandingan glukosa dan dodecanol 2:1.
\end{abstract}

Kata kunci : surfaktan, glukosa, dodekanol, spektroskopi FT-IR, HLB.

\begin{abstract}
Alkyl polyglicoside (APG) is an enviromentally friendly product non-ionic surfactact and biodegradable product that can be obtained by reacting glucose and fatty alcohol. The purpose of this study was to know the manufacture of surfactant alkyl polyglicoside by using glucose and dodecanol, and also to know the effect of catalyst concentration and molar ratio glucose and dodecanol: 1:1; 1:2:2:1 (mol/mol), catalyst consentration of hydrochloric acid: $0.3 \mathrm{M} ; 0,4 \mathrm{M} ; 0,5 \mathrm{M} ; 0,6 \mathrm{M}$ at temperature $100{ }^{\circ} \mathrm{C}$. The analysis in this research using FT-IR spectroscopy, analysis of surface tension (Critical Micelle Concentration) and HLB values (Hidrophylic-Lipophylic Balance). The best catalyst concentration at synthesis of alkyl polyglicoside is $0.6 \mathrm{M}$, the largest surface tension (CMC) at ratio glucose and dodecanol $2: 1$ is $70.7945 \%$ and the highest HLB value is 7.31 in comparison of glucose and dodecanol 2:1.
\end{abstract}

Keywords : surfactant, glucose, dodecanol, FT-IR spectroscopy, HLB

\section{Pendahuluan}

Surfaktan (surface active agent) merupakan bahan yang dapat menurunkan tegangan permukaan suatu cairan dan di antarmuka fasa (baik cair-gas maupun cair-cair), sehingga mempermudah penyebaran dan pemerataan. Kebutuhan surfaktan di Indonesia saat ini mencapai 95 ribu ton per tahun, sedangkan kapasitas produksi dalam negeri sekitar 55 ribu ton per tahun dengan harga surfaktan mencapai US $\$ 16$ per liter yang ke depan harganya terus menanjak. Salah satu surfaktan yang banyak digunakan adalah surfaktan golongan alkil poliglikosida yang banyak digunakan pada detergen, produk herbisida, produk-produk perawatan tubuh, produk kosmetik maupun untuk industri tekstil.

Alkil poliglikosida (APG) dapat diperoleh dengan mereaksikan fatty alkohol dengan karbohidrat menggunakan katalis asam. Salah satu golongan alkil poliglikosida yang banyak digunakan adalah dodecyl poliglikosida yang dapat diperoleh dari fatty alkohol minyak kelapa dan glukosa. Jenis alkil poliglikosida ini mempunyai sifat mudah terurai dan sesuai untuk kulit manusia. Pada penelitian ini akan diproduksi senyawa alkil poliglikosida yaitu dodecyl poliglikosida yang diperoleh dengan mereaksikan glukosa dan dodekanol menggunakan proses asetilasi (direct method), dimana fatty alkohol (dodekanol) dan glukosa direaksikan dengan $\mathrm{HCl}$ sebagai katalis yang prosesnya hanya berlangsung satu tahap. Proses ini dilakukan pada suhu $100{ }^{\circ} \mathrm{C}$ dikarenakan jika pada suhu kurang dari $100{ }^{0} \mathrm{C}$ akan menghasilkan alkil poliglikosida yang kurang murni [2].

\section{Teori}

Surfaktan atau surface active agent merupakan suatu molekul amphipatic atau amphiphilic yang mengandung gugus hidrofilik dan lipofilik dalam satu molekul yang sama. Secara umum kegunaan surfaktan adalah untuk menurunkan tegangan permukaan, tegangan antarmuka, meningkatkan kestabilan partikel yang terdispersi dan mengontrol jenis formasi emulsi, yaitu misalnya oil in water $(\mathrm{O} / \mathrm{W})$ atau water in oil $(\mathrm{W} / \mathrm{O})$.

Surfaktan dibagi menjadi empat bagian penting dan digunakan secara meluas pada hampir semua sektor industri modern.

a. Surfaktan non ionik adalah surfaktan yang tidak bermuatan atau tidak terjadi ionisasi molekul. 
b. Surfaktan Anionik senyawa yang bermuatan negatif dalam bagian aktif permukaan (surfaceactive) atau pusat hidrofobiknya (misalnya RCOO$\mathrm{Na}, \mathrm{R}$ adalah fatty hydrophobe).

c. Surfaktan kationik adalah senyawa yang ditandai dengan adanya muatan positif pada gugus antar muka hidrofobik (hydrophobic surface active).

d. Surfaktan amfoterik adalah surfaktan yang mengandung gugus anionik dan kationik, dimana muatannya bergantung kepada $\mathrm{pH}$, pada $\mathrm{pH}$ tinggi dapat menunjukkan sifat anionik dan pada $\mathrm{pH}$ rendah dapat menunjukkan sifat kationik.

APG adalah surfaktan nonionik yang biasa digunakan pada formulasi beberapa produk seperti formulasi herbisida, produk-produk perawatan badan, produk kosmetik maupun untuk pemucatan kain tekstil.

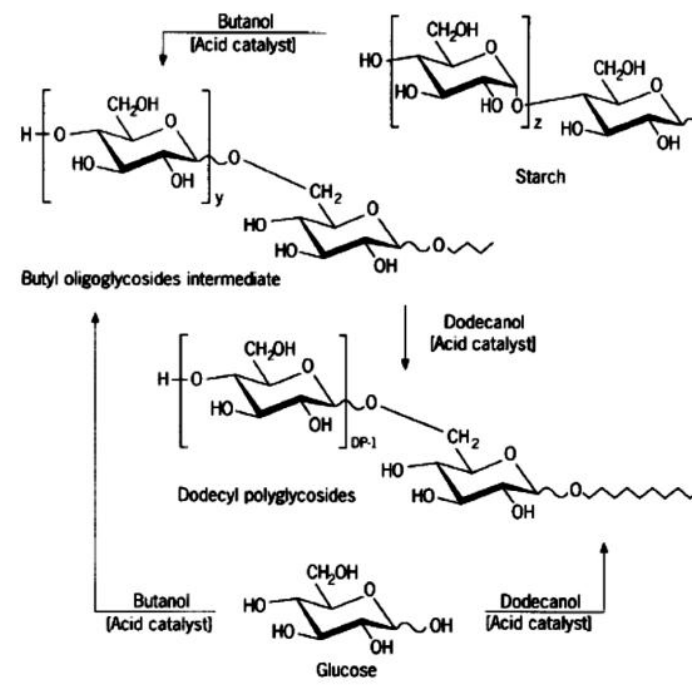

Gambar 1. Proses Reaksi Alkil Poliglikosida

Untuk mengetahui karakteristik kegunaan surfaktan yang dihasilkan maka digunakan standar skala keseimbangan hidrofil-lipofil yang disebut HLB (Hidrophilic Lipophilic Balance) atau dengan kata lain HLB merupakan gambaran untuk pertimbangan hidrofil-lipofil bahan-bahan aktif permukaan. Dengan bantuan harga keseimbangan ini kita dapat membentuk rentang HLB setiap surfaktan secara optimal. Makin besar nilai HLB suatu bahan maka bahan tersebut semakin bersifat hidrofilik.

Tabel 1. Kegunaan surfaktan dilihat dari nilai HLB.

\begin{tabular}{|l|l|}
\hline Nilai HLB & Kegunaan Surfaktan \\
\hline $1-3$ & Antibusa \\
\hline $2-7$ & Emulsifier tipe W/O \\
\hline $7-9$ & Pembasah \\
\hline $8-18$ & Emulsifier tipe O/W \\
\hline $13-15$ & Detergen \\
\hline $15-18$ & Pelarut \\
\hline
\end{tabular}

\section{Metode Penelitian}

Bahan baku yang digunakan dalam penelitian ini adalah glukosa $\left(\mathrm{C}_{6} \mathrm{H}_{12} \mathrm{O}_{6}\right)$ dan dodekanol $\left(\mathrm{C}_{12} \mathrm{H}_{26} \mathrm{O}\right)$, $\mathrm{HCl}$ digunakan sebagai katalis, sedangkan heksana $\left(\mathrm{C}_{6} \mathrm{H}_{14}\right)$ dan air $\left(\mathrm{H}_{2} \mathrm{O}\right)$ sebagai pelarut. Glukosa dilarutkan dengan heksana $200 \mathrm{ml}$, lalu ditambahkan dodekanol dengan rasio perbandingan glukosa dan dodekanol 1:1 mol/mol. Cairan dimasukkan ke dalam labu leher tiga yang dilengkapi dengan pengaduk magnet, termometer, refluks kondensor. Ditambahkan 0,3 $\mathrm{M} \mathrm{HCl}$ sebagai katalis. Didestilasi selama 16 jam dengan suhu operasi $100{ }^{\circ} \mathrm{C}$. Kemudian hasil reaksi didinginkan dan disaring menggunakan corong buchner dan pompa vakum. Filtrat diuapkan dengan menggunakan pendingin leibig. Dipisahkan antara lapisan atas dan lapisan bawah menggunakan corong pemisah. Kemudian lapisan surfaktan dianalisa. Percobaan diulangi dengan variabel yang berbeda yaitu dengan perbandingan rasio molar substrat glukosa:dodekanol $=1: 1 ; 1: 2 ; 2: 1 \quad(\mathrm{~mol} / \mathrm{mol})$, konsentrasi katalis asam klorida $0,3 \mathrm{M} ; 0,4 \mathrm{M} ; 0,5$ M; 0,6 M pada temperatur $100{ }^{\circ} \mathrm{C}$.

Analisa yang akan dilakukan adalah analisa kualitatif dengan menggunakan spektroskopi FT-IR, analisa karakteristik (analisa tegangan permukaan (Surface Tension) dan analisa nilai HLB (Hidrophylic-Lipophylic Balance)) dan penentuan nilai Hidrophylic-Lipophylic Balance (HLB).

\section{Hasil}

\section{A. Analisa Spektroskopi FT-IR}

Alkil poliglikosida yang disintesis memiliki gugus molekul yang bisa diidentifikasi dengan menggunakan FT-IR (Fourier Transform Infrared). Reaksi yang terjadi adalah dari kelompok hidroksil glukosa dengan fatty alkohol dan sebagai hasil reaksi, kondensasi yang terjadi di antara kelompokkelompok $\mathrm{OH}$, untuk pembentukan eter yang diinginkan $\mathrm{C}-\mathrm{O}-\mathrm{C}$ [2].

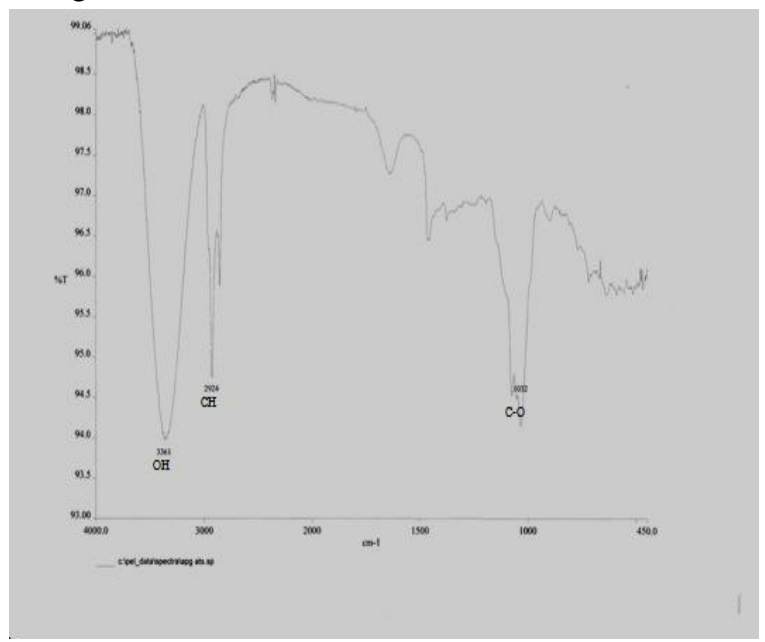

Gambar 2. Spektrum FT-IR Alkil Poliglikosida yang diperoleh. 
Gambar 2 menunjukkan spectrum FT-IR alkil poliglikosida yang diperoleh. Puncak vibrasi pada bilangan gelombang $2924 \mathrm{~cm}^{-1}$ menunjukkan pita uluran $\mathrm{CH}$ sedangkan gugus $\mathrm{OH}$ berada pada bilangan gelombang $3361 \mathrm{~cm}^{-1}$. Terbentuknya alkil poliglikosida didukung oleh spektrum FT-IR dimana memberikan puncak serapan pada bilangan $1032 \mathrm{~cm}$ ${ }^{1}$ yang merupakan vibrasi ulur $\mathrm{C}-\mathrm{O}$. Dari hasil spektrum pembentukan eter C-O-C, maka dapat dapat disimpulkan pembuatan surfaktan dodecyl poliglikosida dapat diperoleh dari proses asetilasi glukosa dan dodekanol.

\section{B. Hubungan Waktu Reaksi terhadap Densitas}

Dari hasil analisa yang dilakukan terlihat bahwa terjadi penurunan densitas setiap variasi konsentrasi katalis terhadap waktu reaksi. Fungsi asam klorida pada reaksi ini adalah untuk mempercepat terbentuknya produk yang diinginkan. Berdasarkan data literatur yang didapat densitas alkil poliglikosida berkisar antara 0,900-1,130 gr/ml.

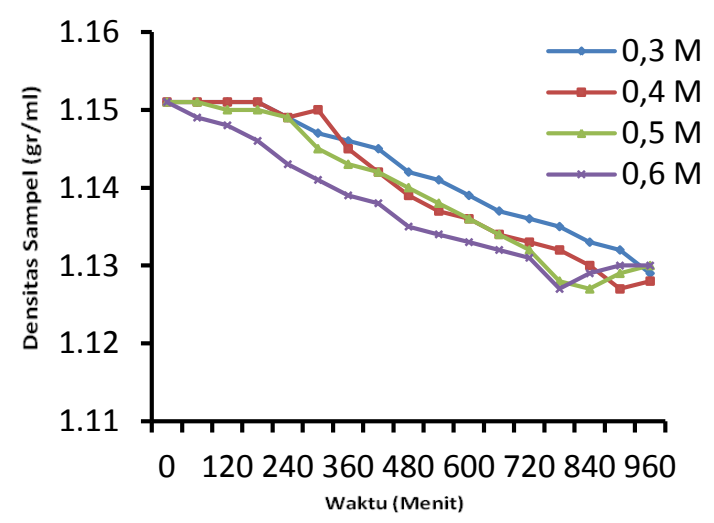

Gambar 3. Grafik hubungan waktu reaksi terhadap densitas pada perbandingan glukosa $:$ dodekanol $=1: 1$

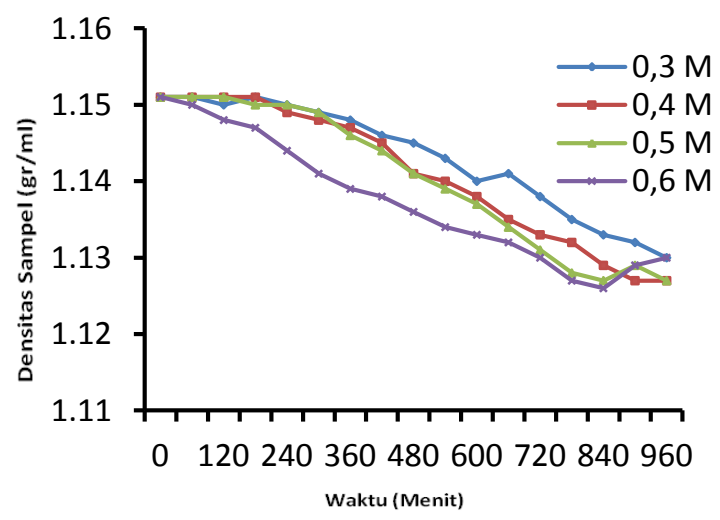

Gambar 4. Grafik hubungan waktu reaksi terhadap densitas pada perbandingan glukosa $:$ dodekanol $=1: 2$

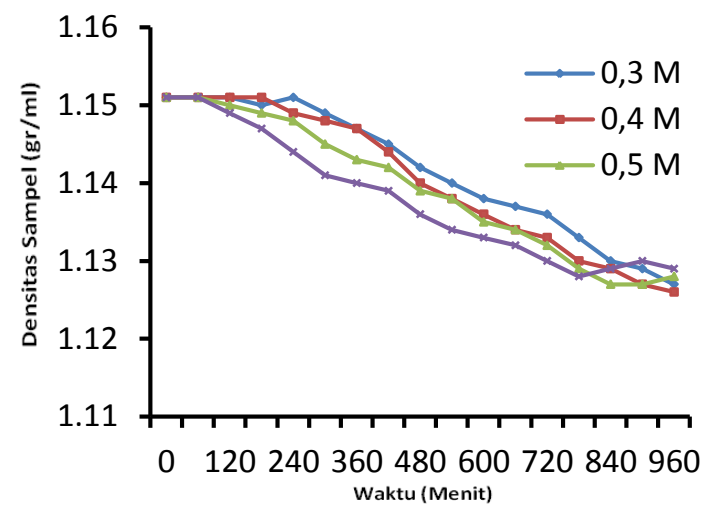

Gambar 5. Grafik hubungan waktu reaksi terhadap densitas pada perbandingan glukosa $:$ dodekanol $=2: 1$

Dari grafik hubungan waktu reaksi terhadap densitas dapat dilihat pada perbandingan rasio mol substrat $1: 1 ; 1: 2$ dan $2: 1$ tidak mengalami perbedaan yang nyata terhadap densitas alkil poliglikosida yang dihasilkan. Pada grafik diatas juga terlihat bahwa pada konsentrasi katalis 0,6 M waktu reaksi semakin cepat. Hal ini disebabkan karena semakin tinggi konsentrasi katalis maka laju reaksi untuk reaktan membentuk produk semakin cepat. Maka dapat diambil kesimpulan bahwa besarnya konsentrasi katalis mempengaruhi lamanya reaksi pada tiap perbandingan mol substrat.

\section{Pengukuran Tegangan Permukaan}

Hubungan tegangan permukaan terhadap $\log -\mathrm{C}$, dapat dilihat tegangan permukaan menurun sejalan dengan naiknya konsentrasi larutan dodecyl poliglikosida dalam air dan akhirnya menjadi konstan walaupun konsentrasi larutan dodecyl poliglikosida bertambah. Hal ini memperlihatkan bahwa dodecyl poliglikosida adalah suatu surfaktan yang mana sebagai gugus hidrofilik adalah gugus hidroksil sedangkan gugus lipofilik adalah gugus hidrokarbon. Pertambahan konsentrasi dodecyl poliglikosida tidak menyebabkan tegangan permukaan bertambah disebabkan karena dodecyl poliglikosida beragregasi membentuk misel. Konsentrasi dimana misel terbentuk disebut Critical Micelle Concentration (CMC).

\section{Rasio glukosa : dodekanol = $1: 1$}

Pada grafik dapat dilihat hubungan tegangan permukaan terhadap $\log$-C pada konsentrasi katalis 0,6 M (Gambar 6) diperoleh 38 dyne/cm dengan CMC sebesar $0,0031 \%$. 


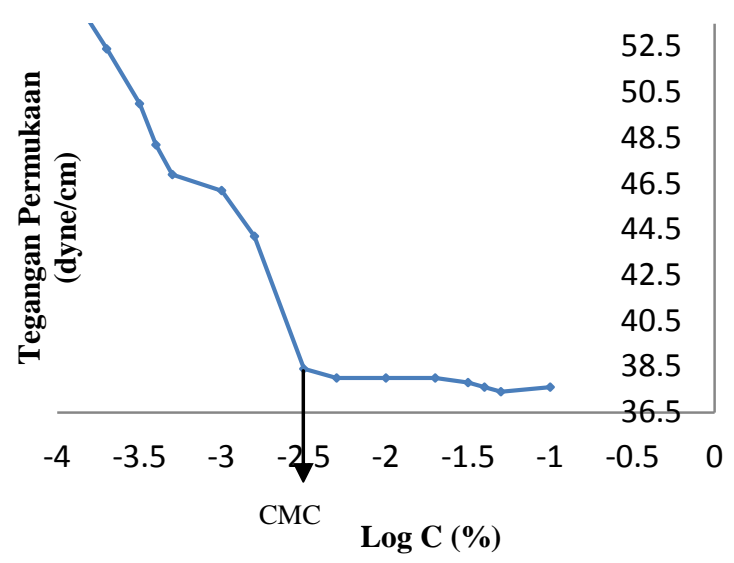

Gambar 6. Kurva Tegangan Permukaan pada rasio 1:1 dan konsentrasi 0,6 M.

\section{Rasio glukosa : dodekanol = $1: 2$}

Pada grafik dapat dilihat hubungan tegangan permukaan terhadap log-C pada konsentrasi katalis 0,6 M (Gambar 7) diperoleh 42,9 dyne/cm dengan CMC sebesar $0,5011 \%$.

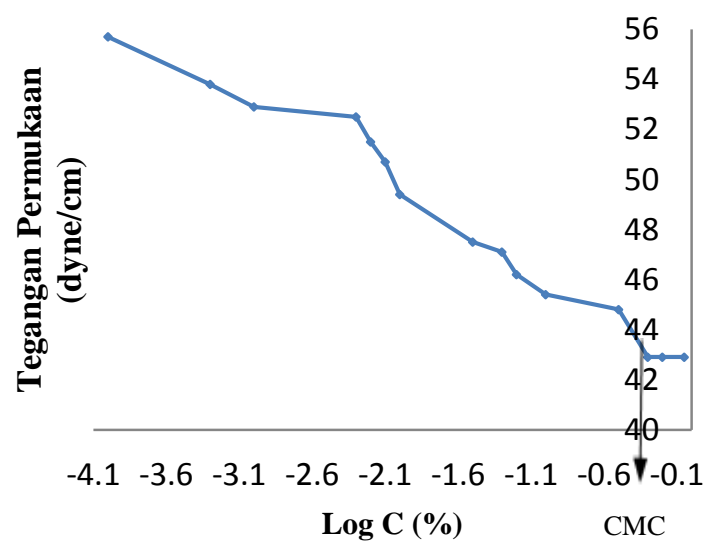

Gambar 7. Kurva Tegangan Permukaan pada rasio 1:2 dan konsentrasi 0,6 M.

Rasio glukosa $:$ dodekanol = $2: 1$

Pada grafik dapat dilihat untuk konsentrasi katalis 0,6 M (Gambar 8) diperoleh 45,6 dyne/cm dengan CMC sebesar 58,8843\%.

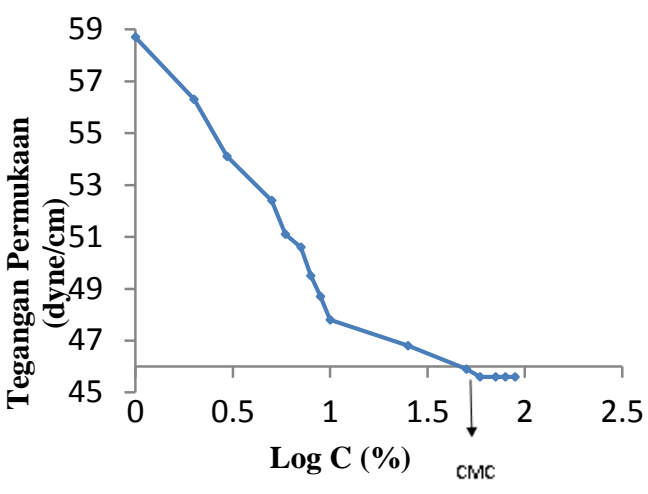

Gambar 8. Kurva Tegangan Permukaan pada rasio 2:1 dan konsentrasi 0,6 M.

Dari grafik-grafik di atas dapat dilihat hubungan tiap rasio reaktan terhadap variasi konsentrasi katalis tidak memiliki nilai CMC yang cukup jauh namun nilai CMC pada rasio reaktan 2:1 sangat berbeda dibandingkan dengan rasio reaktan 1:1 dan 1:2 terdapat perbedaan yang jauh yang mencapai $70,7945 \%$. Semakin tinggi rasio mol reaktan maka nilai penurunan tegangan (CMC) juga semakin tinggi. Surfaktan dinilai semakin baik jika memiliki nilai kemampuan menurunkan tegangan (CMC) semakin tinggi [7].

\section{Penentuan nilai Hidrophylic-Lipophylic Balance (HLB)}

Dari nilai Critical Micelle Concentration (CMC) di atas maka secara teoritis dapat dihitung harga Hidrophylic-Lipophylic Balance (HLB) dengan menggunakan persamaan (1) :

$\mathrm{HLB}=7-0,36 \ln (\mathrm{Co} / \mathrm{Cw})$

dimana: $\mathrm{Cw}=$ Harga $\mathrm{CMC}$

$\mathrm{Co}=100-\mathrm{Cw}$

Harga Hidrophylic-Lipophylic Balance (HLB) yang didapat disesuaikan dengan tabel pengelompokan fungsi surfaktan berdasarkan nilai Hidrophylic-Lipophylic Balance atau HLB (Tabel 1) untuk mendapatkan fungsi dari surfaktan dodecyl poliglikosida untuk tiap rasio reaktan dan variasi konsentrasi katalis.

\section{Rasio glukosa : dodekanol $=1: \mathbf{1}$}

Pada konsentrasi katalis $0,3 \mathrm{M}$ diperoleh nilai HLB sebesar 3,43. Pada konsentrasi 0,4 M didapat HLB 3,48 dan HLB sebesar 3,38 pada konsentrasi katalis 0,5 M serta pada konsentrasi 0,6 M diperoleh HLB 3,26. Dari nilai HLB masing-masing konsentrasi maka dapat diambil kesimpulan bahwa alkil poliglikosida adalah surfaktan hidrofilik yang berfungsi sebagai pengemulsi w/o. 
Rasio glukosa $:$ dodekanol = $1: 2$

Dengan data nilai CMC serta menggunakan tabel nilai HLB (Tabel 1) maka didapatkan pada konsentrasi katalis 0,3 M, nilai HLB sebesar 4,92. Pada konsentrasi 0,4 M, nilai HLB sebesar 5,09 dan HLB sebesar 4,92 pada konsentrasi katalis 0,5 M serta pada konsentrasi 0,6 M diperoleh HLB 5,09. Dari nilai HLB masing-masing konsentrasi pada rasio glukosa : dodekanol 1:2 maka dapat dikatakan bahwa alkil poliglikosida juga adalah surfaktan hidrofilik yang berfungsi sebagai pengemulsi w/o.

\section{Rasio glukosa : dodekanol = $2: 1$}

Dengan cara yang sama, nilai HLB dengan perbandingan bahan baku 2:1 pada konsentrasi katalis 0,3 M, 0,4 M dan 0,6 M diperoleh nilai HLB yang sama sebesar 7,12 sedangkan pada konsentrasi katalis 0,5 M diperoleh nilai HLB sebesar 7,31. Dengan nilai HLB yang diperoleh menunjukkan bahwa alkil poliglikosida juga adalah surfaktan hidrofilik yang berfungsi sebagai pembasah (wettability).

\section{Kesimpulan}

1. Pembentukan alkil poliglikosida dapat diperoleh dari sintesis glukosa dengan dodekanol menggunakan proses asetilasi yang dibuktikan dengan gugus eter yang terbentuk.

2. Besarnya konsentrasi katalis berpengaruh terhadap waktu reaksi, dalam hal ini waktu reaksi yang cepat digunakan konsentrasi katalis $\mathrm{HCl}$ 0,5-0,6 M pada perbandingan bahan baku 1:1 sedangkan pada perbandingan bahan baku 1:2 dan 2:1, reaksi paling cepat terjadi pada konsentrasi katalis $\mathrm{HCl} \mathrm{0,6} \mathrm{M.}$

3. Karakteristik surfaktan yang didapat meliputi:

a. Tegangan Permukaan (CMC) yang diperoleh pada perbandingan bahan baku 1:1 mencapai $0,0058 \%$ pada 38,6 dyne/cm , pada perbandingan 1:2 diperoleh CMC mencapai $0,5011 \%$ pada 42,9 dyne/cm dan pada $2: 1$ sebesar $70,7945 \%$ pada 45,6 dyne/cm.

b. Nilai HLB (Hidrophylic-Lipophylic Balance) pada perbandingan bahan baku 1:1 didapat nilai HLB mencapai 3,48 yang berfungsi sebagai pengemulsi w/o. Pada perbandingan bahan baku 1:2 mencapai 5,09 yang juga berfungsi sebagai pengemulsi w/o dan mencapai HLB sebesar 7,31 pada perbandingan bahan baku 2:1 yang berfungsi sebagai pembasah.

\section{Daftar Pustaka}

[1] Edris, Zarina, Penghasilan Surfaktan Tak Berion Berasaskan Lauril Alkohol daripada Terbitan Minyak Kelapa Sawit, Makmal Pemangkinan, Pusat Pengajian Sains Kimia dan Teknologi Makanan, Fakulti Sains dan
Teknologi, 43600 Universiti Kebangsaan Malaysia, Bangi, Selangor.

[2] El-Sukkary, M.M.A, Síntesis and Characterization of Some Alkyl Polyglycosides Surfactants, 2008.

[3] Genero.R.A, Rhemington's Pharma Ceutical Science, Mack Printing Company, Easton, Pennsylvania USA, 1990.

[4] Johannis, Sintesis Surfaktan Campuran Poliglikil N-etil sisteina, 2008.

[5] Myers, D, Surfactant and Technologhy. New York: John Wiley \& Sons, Inc, 2004.

[6] Nurminah, Mimi, Kajian Pengaruh Rasio Mol Reaktan, Suhu dan Lama reaksi dalam Pembuatan Surfaktan Dietanolamida dari Metil Ester Dominan $\mathrm{C}_{12}$ Minyak Inti Sawit, 2005.

[7] Nuryanto, E, Penelitian Diversifikasi Produk Minyak Sawit, Warta PPKS: Medan,1997.

[8] Zurairah, Masdania, Sintesis Surfaktan Monolauroil Glikoserida dari Hasil Asetilasi Glukosa dengan Monolauroil Gliserol, 2001. 